\title{
The Silent Topic of Sexual Child Abuse in Sports in the Academic Literature: How Network Governance, Public Branding, and Design-Oriented Public Administration Provide Avenues for Future Research
}

\author{
Dr. Vidar Stevens \\ Erasmus School of Behavioral and Social Sciences, Erasmus University Rotterdam \\ Burgemeester Oudlaan 50, 3062PA Rotterdam, The Netherlands \\ Tel: +31 10-4082957Ｅ-mail: stevens@essb.eur.nl
}

Received: Aug 5, 2019 Accepted: Aug. 9, 2019 Online published: Sep. 9, 2019

doi:10.5296/jpag.v9i3.15219 ～URL: https://doi.org/10.5296/jpag.v9i3.15219

\begin{abstract}
In recent years, the topic of sexual child abuse in sports has become a topical issue on the political agenda of many Western countries. Remarkably, where governments have undertaken new policy steps to get a hold on the issue of sexual child abuse in sports, the issue has been a silent topic in the academic literature. Up until 2010, several scholarly articles have been devoted to the topic. Since then, the amount of publications has risen to over one hundred articles, with publication peaks in 2015, 2016, 2017, and 2018. The articles come from different academic disciplines ranging from psychology and criminology to sport sciences, sociology and sport ethics. Given the urgency and relevance of the topic and the immaturity of the research field, we believe it is time to summarize the current literature and propose future directions in such a way that new scientific insights can be of added value to governments' efforts to decrease the amount of child victims of sexual abuse in sport contexts.
\end{abstract}

Keywords: sexual child abuse, sport clubs, branding, design, network governance, public administration

\section{Introduction}

Sexual child abuse in sports has become an urgent topic on the Dutch political landscape. The rise of political attention for this matter started on the $6^{\text {th }}$ of July, 2017 when former football player Renald Majoor shocked the Dutch sport's world with his public statement about the 
horrific sexual abuse he suffered from a young age by one of his coaches (Volkskrant, 2017a). Around the same time, also other sport players opened up about their sexual child abuse experiences by their former trainers and teammates (Volkskrant, 2017b). To get a better overview of the severity of the problem, the Dutch government installed a political commission to examine in-depth the issue of sexual child abuse within all areas of sports during the period 1970-2017.

The conclusions of this commission were presented on the $12^{\text {th }}$ of December, 2017, and they were disturbing: 1 out of 8 children has during his or her sports' career experienced a form of unwanted sexual behavior by trainers or teammates, varying from bullying to assault and rape (De Vries et al., 2017). Consequently, the Dutch government, sports umbrella organizations and the Dutch Olympic Committee (NOC-NSF) have launched various prevention- and support programs to make local sport clubs more aware of sexual child abuse in their associations and to give them tools to protect the children who daily practice on their pitches, running courses or other training facilities. Also other countries, like Germany, UK, France and Australia ${ }^{1}$, have taken serious measures to ban sexual child abuse from the world of sports.

Remarkably, where Western governments have undertaken new policy steps to get a hold on the issue of sexual child abuse in sports, the issue has been a silent topic in the academic literature. Up until 2010, only twenty-seven scholarly articles were devoted to the subject. Since then, the amount of publications has risen to over one hundred articles (see figure 1) with publication peaks in 2015, 2016, 2017, and 2018. The articles come from different academic disciplines ranging from psychology and criminology to sport sciences, sociology and sport ethics. Having seen the urgency and relevance of the topic and the immaturity of the research field, academics have come to believe that it is time to explore and interrogate the current literature and propose future directions in such a way that new scientific insights can be of added value to governments' efforts to decrease the amount of young victims of sexual abuse in sport contexts.

In this article, we specifically look at the articles of the peak years 2015, 2016, 2017 and 2018. We choose to focus on the peak years, because these articles take into consideration the new political urgency of the subject matter and 'modern' context variables, such as the impact of social media and grooming (Owton \& Sparks, 2017). We continue as follows. In the next section, we elaborate on the selection of articles and the methodological approach to examine them. Subsequently, we provide an overview of what in the years 2015, 2016, 2017 and 2018 has been published by scholars about the topic of sexual child abuse in the sports. After that we propose three future avenues for research.

\footnotetext{
1 Australia's Royal Commission Into Institutional Responses to Child Sexual Abuse was initiated on 12 November, 2012 by the then Prime Minister of Australia, Julia Gillard, due to growing concern about the prevalence of child abuse within public and private institutional contexts, and the inadequacy of preventative and responsive measures undertaken by institutions, and active concealment of such abuse by institutions including the Catholic Church and sport organizations (Mathews, 2017:87). Following the advice of this Commission, the Australian government has drawn up several policy actions.
} 


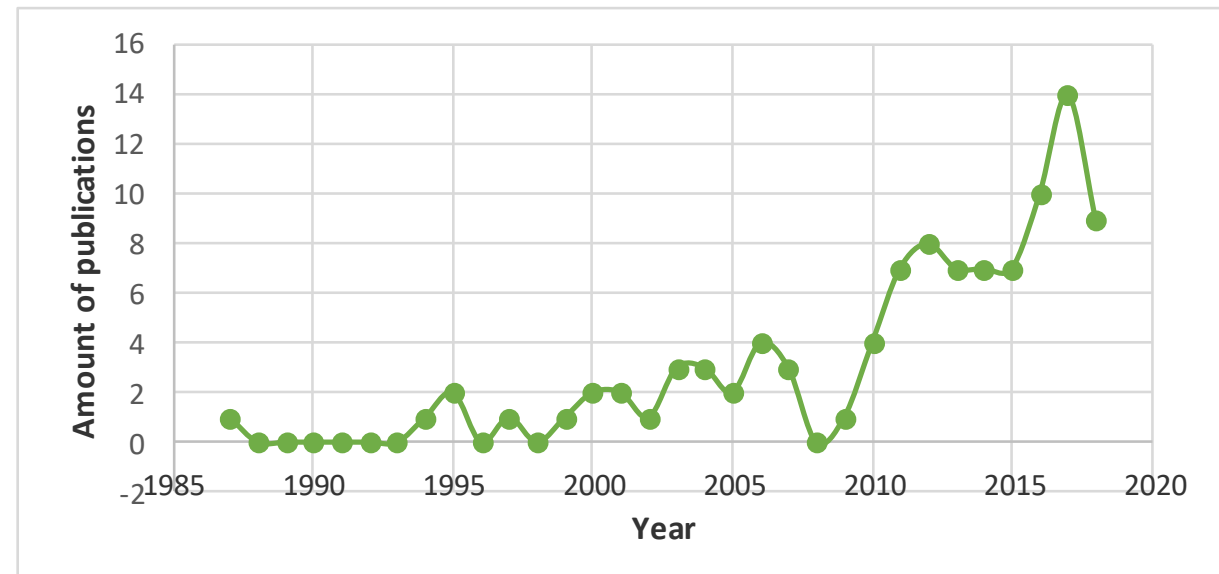

Figure 1. The Trend of Publications on the Topic of Sexual Child Abuse in Sports in the Academic Literature since 1987

\section{Search Strategy and Method of Analysis}

In order to select relevant articles for the review, five search strategies were used. First, the electronic Web of Science database was used to search for articles consisting of the terms [sexual abuse] and [sport] in the title and/or abstract, without a limitation to a specific time period and research domain. The last search was run on June 28, 2019. This resulted in 154 articles. Secondly, every record was manually screened to examine whether the article was related to our topic of interest. We examined the articles by screening titles, abstracts, and when needed, by reading the full text. This resulted in 88 records in the period 1987-2018 (see figure 1). Since we were interested in the knowledge accumulation on the topic of sexual child abuse in sports from 2015 onwards, we continued our search with 41 articles. In our reflections, however, we also refer to important 'older' work that is mentioned in these 'newer' publications.

Thirdly, we conducted a similar search by scanning through the issues (after 2014) in the journals that were most used to publish the articles to see if we missed articles. These journals were: European Journal for Sport and Society, Leisure Studies, Journal of Sport, Education and Society, Australian Social Work Journal, Journal of Aggression, Maltreatment and Trauma, Journal of Sport and Social Issues, and the Journal of Child Abuse and Neglect. 7 articles were added to the list. Fourthly, we looked at the reference list of the 48 articles to see if 'selected scholars' referred in their work to relevant articles published after 2015. In this search, four extra articles were added to the research.

Fifthly, we did a pre-coding for common themes of the 52 articles by looking at four criteria: does the article tell us something about the severity of the problem of sexual child abuse in sports; the most likely victims and perpetrators; organizational factors that contribute to the topic; and public administration related topics more in general. The first three criteria were selected as we believed that these would create more clarity about the setting in which the problem of sexual child abuse in sports takes place. The fourth criteria was broadly defined to capture as many PA themes as possible in our analysis, ranging from organizational culture to 
social network analysis, and from a lack of collaboration between organizations to government's responses to grooming.

Eventually, we started our state of the art reflection of the research field with 31 articles. Between the articles we looked for common themes and interesting findings for the public debate. The results are presented in the next section. We discuss, in subsequent order, how to define sexual child abuse in sports, the severity of the problem, profiles of victims and perpetrators, organizational cultures that foster sexual child abuse in sport clubs, and public administration themes that emerged from the literature study. From thereon, we present three future directions to make the field of research less of a silent topic in the governance and public administration literature.

\section{Common Themes That Emerged From the Literature Search}

\subsection{How to Define Sexual Child Abuse in Sport Settings?}

If we take a look at the articles, not all scholars define how they interpret the concept of sexual child abuse. The articles that do define the concept use different definitions of sexual child abuse in sport contexts. This makes it hard to distill a common or comprehensive definition about what sexual child abuse in sports entails. Some scholars, for example, use the term 'interpersonal violence' to include several forms of violence against young athletes, such as neglect or sexual, physical and psychological abuse (Parent and Fortier, 2017; Vertommen et al., 2016). Again others, such as Alexander et al. (2011), define sexual abuse as a sexual activity for which consent is not or cannot be given. Toftegaard Nielsen (2001) use a continuum of sexual exploitation in which sexual abuse is considered the most severe form of sexual harassment. Besides this conceptual confusion, Palmer and Feldman (2017: 24) make a distinction between abuse of children by adults (referred to adult-child abuse) and the perpetration of sexually harmful behaviours against children by other children (referred to as sexually harmful behaviours by other children) to mark the perpetrator of the harmful behavior. Many scholars, however, refer to policy documents or definitions given by governmental organizations to define what they understand as sexual child abuse in sports (Parent \& Fortier, 2017: 165; Palmer \& Feldman, 2017: 24; Vertommen et al., 2016: 224).

Generally in the sports literature, the model of Fitzgerald et al. (1995) is often used to define and study the problem of sexual violence against youths in sports. Based on this model, negative sexual experience can take the form of sexual harassment (verbal or non-verbal behaviours where the goal is not sexual cooperation, but rather insulting, hostile, and degrading actions), unwanted sexual attention (touching, fondling, including sexual abuse and rape) and sexual coercion (blackmail to obtain sexual favors in return for perceived benefits).

The wide range of definitions in the literature is a severe methodological problem, because as scholars use different 'selection criteria' of what they consider as sexual child abuse, comparison between studies, and as such data accumulation, is often difficult (Vertommen et al., 2016: 224; Parent et al., 2016: 2668). Hence, a general definition of sexual abuse is an important methodological issue to consider for future research. We did not see it as our task 
to come up with an overall definition, as we just tried to give an overview of what is known in the academic literature at large. Nevertheless, we do advise scholars to make in prospective studies use of the model of Fitzgerald et al. (1995), seen the importance of this model in the literature. If scholars decide not to follow this advice, they must make sure that they are very explicit which definitions of prior studies they use to ensure that data accumulation and study comparison is possible.

\subsection{How Severe Is the Problem?}

To study the severity or prevalence of the problem scholars have mainly used a quantitative survey approach. In recent years, there have been quite some quantitative studies which focused on violence against child athletes (Vertommen et al., 2016). The first quantitative studies in the field of sports literature focused mainly on unwanted sexual experiences among female athletes of various ages and found the prevalence of sexual harassment and abuse varying between 2\% and 50\% (Fasting, Chroni, Hervik \& Knorre, 2011; Kirby et al., 2000; Leahy, Pretty \& Tenenbaum, 2002). Contrary to the previous mainstream research positioning females as the most frequent victims of sexual abuse in sports, it seems that the data of Parent and Bannon (2012) and Hartill (2009) confirm that the problem of sexual abuse of boys in sports is underestimated. Looking beyond the distinction between male and female victims, Alexander et al. (2011) recorded in the UK prevalence estimates of $75 \%$ of emotional harm and $24 \%$ of physical harm in athletes under the age of 16 . However, this study suffered from a very low response rate (under 1 percent) and a potential selection bias can therefore not be excluded.

Vertommen et al. (2016) surveyed over 4000 Belgian and Dutch adults regarding their experiences of interpersonal violence before the age of 18 years in the sport context. Results of this study showed that $44 \%$ of the participants reported having experienced at least one form of violence in sport. Specifically, the authors reported $11 \%$ of the respondents experienced physical violence, 38\% experienced psychological violence, and 14\% experienced sexual violence. Another Dutch study on unwanted behaviour in the sport that gauged verbal, physical, and sexual violence (Tiessen-Raaphorst, Lucassen, Van den Dool \& Van Kalmthout, 2008) revealed that 1 out of 5 respondents aged 12 years or older reported to have been a victim (11\%) or a witness of unwanted behaviours including verbal (12\%) or physical aggression (6\%), and sexual harassment (1\%). More recent Dutch data shows that nearly 4 in 10 of those who regularly participate in organized sport experience or witness unwanted behavior (Romijn, Van Kalmthout, Breedveld \& Lucassen, 2013). To date, there is little information in the scientific literature about the violent behavior from parents or other sport authority figures such as sport doctors, massage therapists, sport psychologists, etc. It is also important to note that most available data on violence in sports, come from studies with a primary focus on sexual violence where the perpetrators of this violence were coaches (but see the study of Vertommen et al., 2017; Alexander, Stafford \& Lewis, 2011). So not much is known about the impact of violence against young athletes from teammates.

\subsection{Who Are the Most Likely Victims and Perpetrators?}

Remarkably, there have been limited studies on who the victims of sexual child abuse in 
sports are. Parent and Fortier (2017: 166) even argue that the study of Vertommen et al. (2016) is the first study to include a large sample and to report robust findings in regards to risk factors for becoming a victim of what they call 'interpersonal violence'. In terms of risk factors, Vertommen et al. (idem) reported that ethnic minority, sexual minority (LGBT), athlete disability, and competitive level (international) were all personal characteristics that were significantly overrepresented in the victim sample. In terms of gender, males reported higher prevalence rate of physical violence, whereas females reported more sexual violence. $4 \%$ of the over 4000 respondents were victims of all three forms of violence included in the study (physical, sexual and physiological violence) and were, as such, regarded as 'poly-victims'.

Most media coverage of sexual abuse in sport organizations concern severe cases of child abuse by adult male coaches (Vertommen et al., 2017: 178-180). The coverage of court cases often provides us with an identical picture of the older male coach as the perpetrator. Prevention initiatives, such as the requirement to conduct criminal history checks for aspiring leaders and coaches, have likewise been developed on the assumption that older male adults are the most likely perpetrators of sexual abuse in sports. The findings of the study by Vertommen et al. (2017) disconfirm this 'most-likely perpetrator' notion. Instead in their quantitative study among 1785 respondents in Belgium and the Netherlands, they come up with a more diverse and nuanced perpetrator profile.

First of all, they found that peer athletes (same-age or older) are the most frequently reported perpetrators. Especially concerning psychological and sexual violence, figures go up to $72 \%$ of the reported cases. Only in $19 \%$ of the respondents indicated that one of the perpetrators was a coach. This trend of mainly peer athletes as perpetrators was also observed in other studies, like the study of Alexander et al. (2011). Secondly, the study shows that the majority of the respondents having experienced psychological, physical or sexual violence in sport report more than one perpetrator (Vertommen et al., 2017: 179).

Thirdly, they reported an overwhelming majority of perpetrators to be male. This is in line with the general literature on aggressive behavior, which suggests that men are much more likely to engage in physical and sexual aggression than women (Chesney-Lind \& Pasko, 2003). However, about $70 \%$ of coaching staff in Flanders (Belgium) and the Netherlands is male, which means the exposure to males is significantly higher than exposure to females in sports (Oomens \& Van der Linden, 2015). Although female perpetrators are a minority, female victims of psychological violence accordingly most often report 'several female athletes' as perpetrators.

Fourthly, the results on sexual violence show that 'known others' within the sport organization (excluding coaches and peer athletes) are largely held responsible for sexual transgressions. Rintaugu et al. (2014) indeed demonstrated that spectators appear to be responsible for a sizeable proportion of reported incidents of sexual harassment. In addition, having direct access to athletes, members of the athlete's entourage (e.g. medical staff, and club board members) are potential perpetrators. Following these findings, Vertommen et al. (2017) pleaded for more nuanced (political) discussions about the prevention of sexual child 
abuse in sport settings. In addition, they argue that besides known measures, like criminal history checks, new prevention initiatives should include measures aimed at other likely perpetrator groups.

\subsection{In What Type of Sport Organizations Does Sexual Child Abuse Occur?}

A significant number of sexual abuse cases occurs in institutional contexts, that is, formal organizations that incorporate children among their members (Palmer \& Fieldman, 2017: 24). Formal organizations are collections of people engaged in sustained social interaction coordinated by at least a rudimentary horizontal and vertical division of labor in pursuit of one or more common objectives. Sociologists and public administration scholars understand formal organizations to be 'strong situations', in that they consists of cultures that can override individual predispositions and shape member attitudes and behaviors (Davis-Blake \& Pfeffer, 1989). So far, little is known about the role organizational cultures play in sexual child abuse in sport organizations (Palmer \& Fieldman, 2017: 24). Yet, some indication about the impact of organizational culture in sport organizations on the likelihood of sexual child abuse is given by the study of Palmer and Fieldman (2017) who inter alia, mention three types of harmful organizational cultures: patriarchal culture, macho culture and rape culture.

To start with, the aspect of patriarchal organizational culture, Palmer and Feldman (2017) claim that the cultures of sport organizations often contain content pertaining to their members' gender identities. In contemporary societies, sport organizations tend to contain patriarchal content that includes the assumption that men are inherently active (i.e. capable of knowing and acting in their own interest) while women are passive; the value that this difference between men and women is good; and the norm that this difference should be enacted. These cultural elements allow men greater opportunity to act and assign men's actions greater significance (Butler, 1993). Reflective of this, research shows that in mixed-gender groups, women are afforded fewer opportunities to speak and women's words are given less credence (Hancock \& Rubin, 2015). When a sport organization's culture features these patriarchal cultural elements, it undermines, according to Palmer and Feldman (2017) effective response to child sexual abuse. Instances of sexual child abuse in sport clubs are typically detected by lower-level workers, who must make credible reports about the abuse to persons above them in the organization's hierarchy in order to trigger effective response. However, in most contemporary societies men tend to fill upper-level positions in sport organizations, while women tend to occupy lower-level positions (Weinger, 2015). As a result, many detected instances of sexual child abuse fail to trigger robust institutional responses simply because they are observed by women and communicated to men (Palmer \& Feldman, 2017: 26).

The organizational cultures of some sport organizations contain macho content, which according to (Palmer \& Feldman, 2017: 26) represents an extension of patriarchal content. Macho cultures feature the assumption that men and boys are powerful, active, and competent, rather than passive, helpless, and victimized and include the norm that men and boys should eschew self-concepts that acknowledge weakness, helplessness, and victimization. Macho cultures also embrace the assumption that boys are naturally aggressive 
and innately driven to dominate their peers. Thus, when boys behave aggressively towards their peers in such cultures, adults understand their behavior as 'just boys being boys'. Macho cultures may even showcase the value that boys' aggressive and dominating behavior towards peers is good, because it is assumed beneficial to group functioning. Macho cultures also value tolerance of harsh treatment, because it is assumed indicative of strength and maturity. Finally, macho cultures include the belief that same-sex sexual relationships are deviant (Hartill, 2009). Macho organizational cultures are expressed in a variety of ways, including physically aggressive posturing, verbally aggressive communication, and the use of homophobic taunts (Parkin \& Green, 1997). Hence, Palmer and Feldman (2017: 27) argue that boys may be more prone to perpetrate sexually harmful behaviors and men may be more prone to perpetrate sexual abuse when they are embedded in macho organizational cultures.

Finally, the cultures of some sport organizations contain rape content, which represents an extension of macho content (Feldman \& Palmer, 2017: 27). Rape cultures feature the assumption that men and boys possess strong sexual impulses, while women and girls possess weaker sexual drives. They also feature the belief that men and boys' pursuit of sexual gratification is good, whereas women's and girls' submissiveness is virtuous (Butler, 1993). Indeed, men and boys are assumed to be sexually willing, eager, and aggressive and behavior consistent with these assumptions tends to be valued and considered normative (Buchwald, Fletcher, \& Roth, 2005). Rape culture elements may facilitate the sexual abuse of girls by men and sexually harmful behavior directed at girls by boys (Pringle, 1993). Men and boys embedded in such cultures view the aggressive pursuit of sexual gratification as natural and good. And the aggressive pursuit of sexual gratification by definition entails the satisfaction of sexual desires without consummate consent on the part of the objects of men and boys' sexual desire. As such, an organizational rape culture is another danger for an increased likelihood of sexual child abuse in sport clubs.

\subsection{What Public Administration Topics Emerge From the Literature Study?}

There are only a few articles in the search which touched upon governance and public administration related themes. This again shows the urgency for the field of public governance and public administration to make the topic of sexual abuse in sport clubs a more important topic in scholarly articles. Of course, the main focus of the articles are often the sport clubs and the way they deal with sexual child abuse. However, in preventing and dealing with cases of sexual child abuse in sport settings, sport clubs are dependent on a whole web of public and non-public actors. Therefore, Renfree and Kohle (2019) plead for more research from a public governance perspective. If we look more concretely to the articles of the literature search, two kinds of results emerge which are relevant for policy-makers and public administration scholars: policy recommendations and research gaps.

\subsubsection{Policy Recommendations}

In many of the articles authors come up with recommendations to refine existing policy strategies. An example is the earlier discussed plead of Vertommen et al. (2017) to come up with new prevention initiatives aimed at likely perpetrator groups, other than the most likely 
perpetrator suspect of the older male coach. They argue that new strategies should move beyond known measures like criminal history checks. In similar vein, Kavanagh et al. (2016: 785-786) and Owton and Sparks (2017) warn for new forms of maltreatment of young athletes, like virtual maltreatment through grooming and social media, which are not yet taken up seriously by policy-makers. Lang and Pinder (2017) and Pépin-Gagné and Parent (2016) highlight that in child protection policies little supportive measures are taken to protect youth coaches from false and unfounded allegations. Moreover, Nurse (2018) stresses the importance of implementing child sexual abuse prevention training programs for coaches, and comes up with suggestions for developing and improving these kind of coach-training programs. Specifically, Nurse (2018) points out that education programs should address coaches' particular concerns about contact rules. Coaches want to follow rules, but from the study the result emerges, that they feel that the unique nature of their jobs puts them in situations where it is difficult to comply with fixed behavioral protocols. Training programs should be sensitive to these issues and give coaches space to talk about solutions together.

\subsubsection{Research Gaps}

Besides the policy recommendations, the few articles that were considered 'public administration and governance articles', speak of three particular research gaps that are in need of more scholarly exploration: more research on the governance capacity of sport clubs (Renfree \& Kohle, 2019), new ways to increase awareness of the topic of sexual child abuse and bind actors to prevent it from happening (Delawarde-Saïas et al., 2018), and the call to overcome the mismatch between the victims' ways of coping with abuse, and the policies aimed to prevent it and support victims of sexual abuse in sports (Kavanagh et al., 2017). We summarize each of these research gaps in greater detail in the following sections, and, simultaneously, we propose avenues for future research for the public governance and public administration field to fill these research gaps.

\section{Avenues for Future Research}

\subsection{Future Avenue one: Network Governance to Increase Sport Club's Governance Capacity}

Different scholars discussed the governance complexity of the sports sector (Renfree \& Kohle, 2019; Lucassen \& De Bakker, 2016). Renfree and Kohle (2019: 2), for example, write regarding the UK sports sector, "the complexity of sport in the United Kingdom is unique and key organizations include a mixture of public bodies, such as quasi-autonomous governmental organizations (QUANGO's), non-departmental bodies (NDPB's), like Sport England, UK Sport, and regional sport boards, local authorities, Higher Education institutions, and voluntary and private bodies." In practice many of these organizations operate at distance from the central government in that they receive state funding, operate within associated regulatory frameworks, and assume varying degrees of autonomy and decision-making capacity. Yet, as Bergsgard et al. (2007) argue, the feeling of autonomy of sport clubs or organizations involved in sport policy is purely symbolic. Organizations and clubs actually work to more explicit agendas set by the State via, in case of the UK, the Department of Digital, Culture, Media, and Sports (DCMS). One of these policies is the prevention of sexual child abuse within sport clubs. Notwithstanding sport clubs' laudable intentions to support 
National Sport agendas (often with limited resources, little guidance from National Governing bodies, and only a few volunteers), Renfree and Kohle (2019) point out that clubs face considerable practical, ideological, political and governance constraints that adversely affect their day-to-day operations.

One of the most critical constraints is the lack of overview to what other organizations (like governmental organizations, healthcare organizations or private bodies) sport clubs are related to in the prevention of sexual child abuse (Wäsche, Dickson, Woll \& Brandes, 2017). Hence scholars argue that sport research, "is in need of social network analysis to gain a better understanding of the relational dynamics sport clubs face in their daily activities." Specifically, Wäsche et al. (2017: 142) state that within sport research more attention must be devoted to: what kind of actor networks exist surrounding sport clubs? Where do certain network structures come from (network formation)? What is the structure of certain networks (network description)? And what are the consequences of certain network structures (network effects)?

Although the call for more research on social networks in sport research is very relevant, we want to highlight that within public administration and governance research, the literature on social networks, collaboration, or other related concepts such as horizontal coordination, steering, or network governance, is not new (Hanf \& Scharpf, 1978; Scharpf, 1994; Klijn \& Koppenjan, 2016; Ansell \& Torfing, 2014). Neither is the idea new that organizations, like governmental organizations or sport clubs, are increasingly dependent on each other, and on other organizations outside government, for their policy design and implementation (Klijn \& Koppenjan, 2016: 22). We see a huge potential for public administration and governance literature to add to theory development in the field of sport research. Especially when it comes to the topic of network management (Klijn \& Koppenjan, 2016). Hence, we suggest that sport studies also devotes more attention to theories of network interventions and network management. Both concepts are important aspects of making purposefully use of network structures in the collaboration for preventing sexual child abuse in sport settings to occur.

Recently, within the network governance literature an interesting body of studies has emerged that specifically looks at the generative mechanisms of collaborations and network settings. Generative mechanisms can best be understood as the processes by which a causal relation comes about; in our case, why collaboration actually leads to measures aimed at reducing sexual child abuse in sport settings. Oftentimes, three generative mechanisms are mentioned in the literature: synergy, commitment and learning (Ansell \&Torfing, 2014: 11). Synergy is by Ansell and Torfing (2014: 11) defined as a social process in which actors bring together complementary resources or capabilities (i.e. resource-sharing). Commitment, then, is understood as the social process through which actors in groups build consensus and support for a particular plan or implementation strategy (Ansell \& Torfing, 2014: 11). Lastly, learning is considered as the social process whereby cognitive change occurs as a result of interaction between different actors, which can transform or reframe the collective sense of possibility or generate new ideas to target issues of abuse in sport clubs (Ansell \& Torfing, 2014: 11). 
Most of these studies have, however, been rather superficial when it comes to making inferences about the dynamics in which these three generative mechanisms operate (Ansell \& Torfing, 2014: 238-239). That is to say, scholars have not been very explicit about how, when and why individual actors are likely to engage with other actors in practices of learning, resource-sharing and consensus-building in collaborative settings. In point of fact, the only behavioural insight that can be derived from existing (case) studies is that not all actors have the same propensity, or ability, to engage with other actors in these three generative processes (Stevens, 2018). This lack of scholarly attention to the behavioural manifestations of actors is striking, as it means that we (i.e. the academic community) actually have little knowledge about the interactive dynamics within collaborative processes, and thus also, for example, about the manner in which emergent interaction patterns between actors impact the quality of the generative mechanisms in terms of their contribution to the development, realization and propagation of proposals for preventing or solving matters of sexual abuse in sport clubs.

From a more critical stance, it can even be argued that on the whole scholars have only put a little effort in scrutinizing accepted truisms about the interactive dynamics and corresponding benefits that arise from collaborative processes (Ansell \& Torfing, 2014: 238-239), like 'collaborative interaction facilitates trust-based circulation and cross-fertilization of new and creative ideas between actors' (Sørensen \& Torfing, 2012: 5). To this end, we argue that for scientific purposes (in terms of scientific progress), and in order to gain a better notion of the value of network processes as vehicles for the development of policies aimed at reducing sexual violence and abuse in sport settings, it would be wise to devote in prospective studies more attention to the determinants that explain why individual actors engage in, or refrain from, interacting with some actors and not with others in collaborations within the sport sector.

A perfect method to perform this type of research is the Exponential Random Graph Modelling (ERGM) method. ERGM is a statistical network method that aims to explain tie-formation. This means that with the help of ERGMs a scholar is able to draw inferential conclusions about why individual actors have the tendency to connect with some actors and not with others in networks. This outcome variable (i.e. tendency to connect or not), and thereby the overall purpose of the methodological tool, thus makes the ERGM-methodology well-equipped for making inferences about the micro-level interactive actor dynamics in sport networks.

Documentation about the functioning and operational system behind ERGMs is well established in the literature (Scott, 2015). Scholars have written detailed accounts about: the basic principles of the statistical network model, the guidelines for performing the analysis, checking the network assumptions, diagnostics and interpreting the results, the algorithm and the formulas of ERGM-models, the jargon of these models in graph-theoretical language, and how to retrieve and use the ERGM-package ${ }^{2}$ from the Comprehensive R Archive Network (Handcock et al., 2019). The available literature on ERGM is, however, highly technical and

\footnotetext{
${ }^{2}$ See the website: https://cran.r-project.org/web/packages/ergm/index.html
} 
largely inaccessible. In fact, most work on the methodology has been written by and for statisticians (but see Harris, 2014). These articles are full of complex equations that a scholar has to grasp first, before being able to get a basic understanding of ERGMs. This may cause that applied scholars - to which we also consider ourselves - feel quite some anxiety with utilizing the ERGM methodology, and in the worst case even decide to avoid working with it. Therefore, Stevens and Verhoest (2016), Stevens (2018), and Stevens (2019) have written introduction articles for scholars to become more acquainted with the ERGM methodology.

\subsection{Future Avenue Two: Public Branding to Bind Actors, Create Awareness and Change Norms}

From the previous section, one can notice that sexual child abuse at sport clubs can be regarded as a wicked problem, as it involves many actors who have different responsibilities and opinions about how to cope with the issue. Surrounding the topic also a diversity of emotions exist; ranging from anger and guilt to helplessness, fear and anxiety. In addition, the abuse often takes place in anonymous settings, far away from the 'outside world' where people can keep an eye on each other. These characteristics make it hard for sport clubs, local governments, or health organizations to tame the issue and get a hold on it. It therefore demands that governments change their relationship with sport clubs and health organizations from top-down steering to more interactive forms of governance as a way to create synergies in the effort to protect victims of sexual abuse in sport settings (Delawarde-Saïas et al., 2018).

Public branding is one of the new and promising upcoming governance strategies that allows governments to bind actors to a policy issue and create greater awareness of a topic. A brand is a deliberately developed symbolic construct to identify a phenomenon and differentiate it from similar phenomena by adding particular meaning to it (Eshuis \& Klijn, 2012). Politicians use branding, including brand elements like slogans, wordmarks, and logos, to construct an identity that is attractive to voters (Eshuis \& Klijn, 2012: 4). Branding is also frequently used to promote public organizations, policies or services (Teodoro \& An, 2017, Karens, Eshuis, Klijn \& Voets, 2016). Moreover, one of the most utilized forms of public branding, 'place branding', is used by local governments to boost certain areas for revenue (Stevens, 2019). Another form of branding present in the literature is 'health branding' (Evans, Blitstein, Vallone, Post \& Nielsen, 2015). The goal of health branding is to increase uptake and engagement with health interventions. Often, health branding is used in health campaigns to promote new healthy ways of living or medicines.

We see potential for branding as a strategy to create more awareness and political action for the topic of sexual abuse in sport organizations. Public brands can be used to bind people (creating brand loyalty through establishing emotional bonds), activate people, make people aware of an issue, or communicate with media. Branding processes can be organized in participatory ways if actors are involved in the development of brand elements or underlying brand values. Participatory branding, for example, allows victims, sport clubs or health organizations to contribute to the image, develop a shared brand identity, and for instance add or upload their own stories of abuse to the brand (video's, short impressions of events, measures initiated at sport clubs or in the neighborhood etc.). In this way brand communities 
can be created (Muniz \& O'Guin 2001). Communities are groups of people who feel they have a shared identities by sharing particular symbols and norms. In this way, brands can also be used to break through harmful organizational cultures, like the earlier discussed patriarchal, macho, and rape culture. Furthermore, building brand communities also creates more resilience, as brands can mobilize people, and enhance and sustain participation and collective action to tackle social problems, like sexual child abuse in sport clubs.

We encourage scholars to search in prospective studies for an answer to the following research questions: under what circumstances can branding or social marketing increase awareness for the issue of sexual child abuse in sport clubs? When are victims willing to join a public branding campaign? How long does the impact of a public branding campaign last in people's minds? And under what conditions does a public branding campaign foster collaborations between health organizations, local governments and sport clubs? Experiments and focus groups are the right methodological instruments to find answers to these research questions.

\subsection{Future Avenue Three: Design Research as Instrument to Redraft Policies to Support Victims}

Kavanagh et al. (2017) point out that the full coping processes of victims of emotional and sexual abuse often happens over a period of more than 10 years. They also state that the coping of victims with their experiences is, however, not well understood by scholars. In consequence, policies and support, aimed at helping sport victims of abuse with coping with their experience fall short. To this end, Kavanagh et al. (2017), but also other scholars such as Fasting et al. (2007), Rodriquez and Gill (2011), and Sterling and Kerr (2007), explored athlete coping responses to emotionally and sexually abuse behaviors. From their studies, the image emerges that in the beginning of sexual abuse coping strategies are implemented by athletes primarily to alleviate feelings of distress. In the instance that abuse occurred, participants demonstrated a reliance on coping methods that enabled them to continue competing or performing. Most of the participants in the study point out that they coped with the abuse in isolation and remained silent about what they were experiencing. Over time, athletes moved from private attempts of coping to seeking support from formal and informal support structures. As such, the study of Kavanagh et al. (2017) inter alia highlights the temporal nature of coping with emotional and sexual abuse. Particularly, they distinguish the temporal dimensions of 'coping in the moment', 'coping over time', and 'post-experience' (see table 1). 
Table 1. Coping with Emotional Abuse, table retrieved from Kavanagh et al (2017: 408).

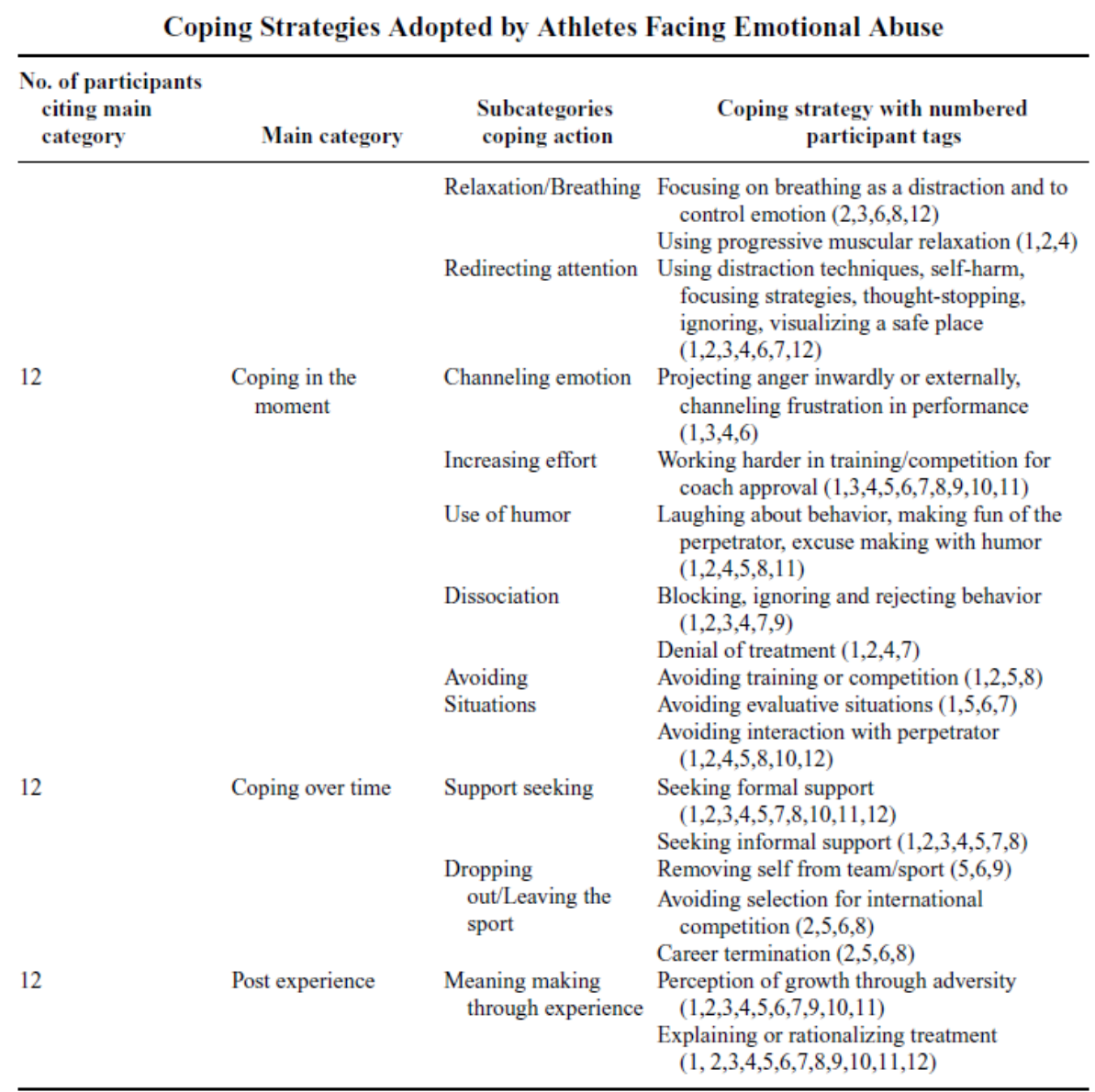

Following the finding of the temporal nature of victims' coping processes, Kavanagh et al. (2017: 414-415) argue that a number of practical implications arise from their study. Amongst other things, they make the case for recalibrating policy measures and re-organizing (social) support structures. They, however, do not offer any methodological pathways to adjust existing measures and structures. We believe that design-oriented public administration research is well-suited for the research question that Kavanagh et al. (2017) leave open for future research.

Recently, there is a growing interest in the application of design approaches, methods and design thinking in public administration, on account of its potential to innovate policymaking and governing practices (Bason, 2016). Design methodology is expected to provide smarter and more agile ways to identify problems, opportunities and solutions. Attention for design is not new in public administration. Herbert Simon (1969) defined public administration as one the sciences of the artificial and thus as a design science. A design science distinguishes itself from the natural sciences because it studies the artificial, or man-made, instead of the natural and as such, deals with the contingent instead of the necessary - with how things might be instead of with how things are. Simon argues that the core of designing, and as such of all professional training, is the ability to deal with situations as one encounters them by both 
diagnosing the problem and devising a way to deal with it. A designer can, as such, create a solution for, for example, a material artefact, but also a treatment plan for a victim of sexual abuse, or a certain policy. The idea of public administration as a design science is thus an old one, but types of research that have followed from it have changed over the years has, resulting in new methods and techniques from the design field now being incorporated in public administration (Bason, 2016).

Stevens (2019) shows that a design approach normally consists of four key stages of development, to mention: user-centered design research, minimum viable product development, proto-testing, and instrument evaluation. The user-centered research design phase is an iterative design process in which designers focus on the end-users of a policy, process, or program, and their specific needs. In the case of victims' coping strategies, designers can focus in this stage on the victims, their coping behaviors, their needs to find social support, and the way how to organize the social support in such a way that it is most beneficial for the victim. User-centered research design starts with the mapping of the different types of victims and their individual needs. This information can be obtained through investigative (e.g. surveys and interviews) and generative (i.e. brainstorming sessions) research methods, which help designers to reveal what the specific user needs are. Ultimately, this phase enables the development of tailor-made policies, programs, and processes that enable better coping with a victim's abuse experiences. Following the outcomes of the user-centered design research phase, a minimum viable product can be developed. A minimum viable product can be regarded as the most simplistic version of a policy, program or process. It has just enough functions to be launched and to provide feedback for future 'product' development. In the third phase of the design process, a minimum viable product is proto-tested. In this way, new end user's information can be retrieved, flaws and gaps in the policy can be corrected for, and suggestions for optimizing prevention processes or support structures can be shared by linking end-users to designers. This information can eventually be used in the fourth phase of design (i.e. instrument evaluation) as a means to refine policies, programs, and processes.

We expect that the use of design methods can lead to new processes, prevention programs and support structures that are more victim-centered (instead of problem-centered), as design approaches generally have an openness to inquiry and creativity that helps develop new (policy) options. To this end, we encourage the emergence of design labs and policy experiments focusing on the prevention and support of coping with sexual and emotional abuse of athletes in sport settings. Notwithstanding the potential of design research, we do, however, want to warn researchers to be careful in treating 'victims' as Guinea pigs. Talking about abuse and coping mechanisms can be a very emotional and traumatic endeavor for victims. Therefore, victims must be approached carefully in design settings, and, the talks can best be supervised by a sport psychologist to also understand how much stress or 'research-activity' a participant can bare.

\section{Final Reflection}

To conclude, this paper calls attention to the importance of more public administration and 
governance research focusing on the topic of sexual child abuse in sport settings. While earlier studies have certainly contributed to our understanding of the different forms of sexual child abuse, typical victims and perpetrators, the severity of the problem, and the general organizational conditions that increase sexual child abuse in sport clubs, we argued that there are also certain shortcomings in our current knowledge. These relate, especially, to the governance capacity of sport clubs, new ways to bind actors, create awareness of the problem and change norms, and the disconnection between policies and support, aimed at helping sport victims of abuse with coping with their experience, and victims' personal coping strategies. To overcome these research gaps we proposed three future research venues. Specifically, we see quite some value for incorporating network governance research, branding research, and design-oriented research approaches into the field of sexual child abuse at sport clubs. Relevant methodologies to conduct such a kind of research are the method of Exponential Random Graph Modelling, experiments, focus groups and design studies. In the end, we hope that this paper contributes to the exploration of new avenues in the field of sexual child abuse in sport settings, and encourages scholars to add new equipment to their methodological toolbox by making use of relatively new research methods, like ERGMs, experiments and design studies. In this way, academia can help governments, sport organizations, and other involved actors, with designing better policy measures to deal with the issue of sexual child abuse in sport settings.

\section{Acknowledgement}

This project has received funding from the European Union's Horizon 2020 Research and Innovation Programme under grant agreement No. 726840 (TROPICO), and the Erasmus Initiative Vital Cities and Citizens of Erasmus University Rotterdam. Thanks for the Royal Dutch Institute in Rome (KNIR) to invite me over for a research stay to finish the article.

\section{References}

Abebe, K. Z., Jones, K. A., Ciaravino, S., Ripper, L., Paglisotti, T., Morrow, S. E., \& Miller, E. (2017). A cluster-randomized trial of a middle school gender violence prevention program: Design, rationale, and sample characteristics. Contemporary Clinical Trials, 62, 11-20. https://doi.org/10.1016/j.cct.2017.08.007

Ahmed, M. D., Van Niekerk, R. L., Yan Ho, W. K., Morris, T., Baker, T., Khan, B.A., \& Tetso, A. (2018). Female student athletes' perceptions of acceptability and the occurrence of sexual-related behavior by their coaches in India. International Journal of Comparative and Applied Criminal Justice, 42(1), 33-53. https://doi.org/10.1080/01924036.2017.1310661

Alexander, K., Stafford, A., \& Lewis, R. (2011). The Experiences of Children Participating in Organized Sport in the UK. London, United Kingdom: NSPCC.

Ansell, C., \& Torfing, J. (2014). Public Innovation through Collaboration and Design. New York, NY: Routledge. https://doi.org/10.4324/9780203795958

Bason, C. (2016). Design for Policy. Abingdon, United Kingdom: Routledge. https://doi.org/10.4324/9781315576640

Bergsgard, N. A., Houlihan, B., Mangset, P., Nødland, S. I., \& Rommetveldt, H. (2007). Sport policy. A comparative analysis of stability and change. Abingdon, United Kingdom: 
Routledge.

Buchwald, E., Fletcher, P., \& Roth, M. (1995). Transforming a Rape Culture. Minneapolis, MN: Milkweed Editions.

Butler, J. (1993). Bodies That Matter: On the Discursive Limits of Sex. New York, NY: Routledge.

Chesney-Lind, M., \& Pasko, L. J. (2003). The Female Offender: Girls, Women and Crime. Thousand Oaks, CA: Sage Publications.

Davis-Blake, A., \& Pfeffer, J. (1989). Just a mirage: The search for dispositional effects in organizational research. Academy of Management Review, 14(3), 385-400. https://doi.org/10.5465/amr.1989.4279071

De Vries, K., Ross-Van, D. C., Myjer, E. (2016). Rapport van de Onderzoekscommissie Seksuele Intimidatie en Misbruik in de Sport. Eindoven, The Netherlands: PreVision.

Delawarde-Saïas, C., Gagné, H., Brunson, L., \& Drapeau, S. (2018). Implementing a multilevel prevention strategy under an intersectoral partnership: The case of the Triple $\mathrm{P}$ Program. Children and Youth Services Review, 88, 170-179. https://doi.org/10.1016/j.childyouth.2018.03.009

Eshuis, J., \& Klijn, E. H. (2012). Branding in Governance and Public Management. Abingdon, United Kingdom: Routledge. https://doi.org/10.4324/9780203145159

Evans, W. D., Blitstein, J., Vallone, D., Post, S., \& Nielsen, W. (2015). Systematic review of health branding: growth of a promising practice. Translational Behavioral Medicine, 5(1), 24-36. https://doi.org/10.1007/s13142-014-0272-1

Fasting, K., Chroni, S., Hervik, S. E., \& Knorre, N. (2011). Sexual harassment in sport toward females in three European countries. International Review for the Sociology of Sport, 46(1), 76-89. https://doi.org/10.1177/1012690210376295

Fitzgerald, L. F., Gelfand, M. J., \& Drasgow, F. (1995). Measuring sexual harassment: Theoretical and psychometric advances. Basic and Applied Social Psychology, 17(4), 425-445. https://doi.org/10.1207/s15324834basp1704_2

Giaccard, S., Ward, L. M., Seabrook, R. C., Manago, A., \& Lippman, J. R. (2017). Media Use and Men's Risk Behaviors: Examining the Role of Masculinity Ideology, Sex Roles, 7, 581-592. https://doi.org/10.1007/s11199-017-0754-y

Gleaves, T., \& Lang, M. (2017). Kicking “No-Touch” Discourses Into Touch: Athletes' Parents' Constructions of Appropriate Coach-Child Athlete Physical Contact. Journal of Sport and Sport Issues, 41(3), 191-211. https://doi.org/10.1177/0193723517705543

Hancock, A. B., \& Rubin, B. A. (2015). Influence of Communication Partner's Gender on Language. Journal of Language and Social Psychology, 34(1), 46-64. https://doi.org/10.1177/0261927X14533197

Handcock, M. S., Hunter, D. S., Butts, C. T., Goodreau, S. M., Krivitsky, P. N., Morris, M., \& Bender-de, M. S. (2019). Fit, Simulate and Diagnose Exponential-Family Models for Networks. The Comprehensive R Archive Network. Accessed August 4, 2019 at: https://cran.r-project.org/web/packages/ergm/ergm.pdf. 
Hanf, K., \& Scharpf, F. W. (1978). Interorganizational policy making: limits to coordination and central control. Thousand Oaks, CA: Sage Publications.

Harris, J. K. (2014). An Introduction to Exponential Random Graph Modelling. London, United Kingdom: Sage Publications. https://doi.org/10.4135/9781452270135

Hartill, M. (2009). The sexual abuse of boys in organized male sports. Men and Masculinities, 12(2), 225-249. https://doi.org/10.1177/1097184X07313361

Johansson, S. (2017). 'This might be him; the guy I'm gonna marry': Love and sexual relationships between female elite-athletes and male coaches. International Review fort the Sociology of Sport, 52(7), 819-838. https://doi.org/10.1177/1012690215626593

Johansson, S. (2018). 'Am I sexually abused?' Consent in a coach-athlete lesbian relationship. Sport, Education and Society, 23(4), 311-323.

https://doi.org/10.1080/13573322.2016.1202819

Karens, R., Eshuis, J., Klijn, E.H., \& Voets, J. (2016). The Impact of Public Branding: An Experimental Study on the Effects of Branding Policy on Citizen Trust. Public Administration Review, 76(3), 486-494. https://doi.org/10.1111/puar.12501

Kavanagh, E., Brown, L., \& Jones, I. (2017). Elite Athletes' Experience of Coping With Emotional Abuse in the Coach-Athlete Relationship. Journal of Applied Sport Psychology, 29(4), 402-417. https://doi.org/10.1080/10413200.2017.1298165

Kavanagh, E., Jones, I., \& Sheppard-Marks, L. (2016). Towards typologies of virtual maltreatment: sport, digital cultures \& dark leisure. Leisure Studies, 35(6), 783-796. https://doi.org/10.1080/02614367.2016.1216581

Kirby, S. L., Greaves, L., \& Hankivsky, O. (2000). The dome of silence sexual harassment and abuse in sport. Halifax, N.S.: Fernwood.

Klijn, E. H., \& Koppenjan, J. F. M. (2016). Governance networks in the public sector. London, United Kingdom: Routledge.

Kwak, Y., Mihalec-Adkins, B., Mishra, A. A., \& Christ, S. L. (2018). Differential impacts of participation in organized activities and maltreatment types on adolescent academic and socioemotional development. Child Abuse \& Neglect, 78, 107-117. https://doi.org/10.1016/j.chiabu.2017.09.026

Lang, M., \& Pinder, M. (2017). Telling (dangerous) stories: a narrative account of a youth coach's experience of an unfounded allegation of child abuse. Qualitative Research in Sport, Exercise and Health, 9(1), 99-110. https://doi.org/10.1080/2159676X.2016.1246469

Leahy, T., Pretty, G., \& Tenenbaum, G. (2002). Prevalence of sexual abuse in organised competitive sport in Australia. Journal of Sexual Aggression, 8(2), 16-36. https://doi.org/10.1080/13552600208413337

Lucassen, J. M. H., \& De Bakker, S. (2016). Variety in hybridity in sport organizations and their coping strategies. European Journal for Sport and Society, 13(1), 75-94. https://doi.org/10.1080/16138171.2016.1153880

Mathews, P. (2017). Optimizing implementation of reforms to better prevent and respond to child sexual abuse in institutions: Insights from public health, regulatory theory, and Australia's Royal Commission. Child Abuse \& Neglect, 74, 86-98. 
https://doi.org/10.1016/j.chiabu.2017.07.007

McPherson, L., Long, M., Nicholson, M., Cameron, N., Atkins, P., \& Morris, M. E. (2017). Secrecy Surrounding the Physical Abuse of Child Athletes in Australia. Australian Social Work, 70(1), 42-53. https://doi.org/10.1080/0312407X.2016.1142589

McPherson, L., Long, M., Nicholson, M., Cameron, N., Atkins, P., \& Morris, M. E. (2017). Children's experience of sport in Australia. International Review fort the Sociology of Sport, 52(5), 551-569. https://doi.org/10.1177/1012690215608517

Moola, F., \& Krahn, A. (2018) A Dance with Many Secrets: The Experience of Emotional Harm from the Perspective of Past Professional Female Ballet Dancers in Canada. Journal of Aggression, Maltreatment \& Trauma, 27(3), 256-274. https://doi.org/10.1080/10926771.2017.1410747

Muniz, A. M., \& O'Guinn, Th. C. (2001). Brand community. Journal of Consumer Research, 27(4), 412-432. https://doi.org/10.1086/319618

Nurse, A. M. (2018). Coaches and child sexual abuse prevention training: Impact on knowledge, confidence, and behavior. Children and Youth Services Review, 88, 395-400. https://doi.org/10.1016/j.childyouth.2018.03.040

Ohlert, J., Seidler, C., Rau, T., Bettina, R. B., \& Allroggen, M. (2018). Sexual violence in organized sport in Germany. German Journal of Exercise and Sport Research, 48(1), 59-68. https://doi.org/10.1007/s12662-017-0485-9

Oomens, M., \& van der Linden, J. (2015). Sportkadermonitor 2015. Utrecht. Accessed August 4, 2019 at: http://www.nocnsf.nl/sportkadermonitor.

Owton, H., \& Sparkes, A. C. (2017). Sexual abuse and the grooming process in sport: Learning from Bella's story. Sport, Education and Society, 22(6), 732-743. https://doi.org/10.1080/13573322.2015.1063484

Palmer, D., \& Feldman, V. (2017). Toward a more comprehensive analysis of the role of organizational culture in child abuse in institutional contexts. Child Abuse \& Neglect, 74, 23-34. https://doi.org/10.1016/j.chiabu.2017.08.004

Parent, S., \& Bannon, J. (2012). Sexual abuse in sport: What about boys?. Children and Youth Services Review, 34(2), 354-359. https://doi.org/10.1016/j.childyouth.2011.11.004

Parent, S., \& Fortier, K. (2017). Prevalence of Interpersonal Violence against Athletes in the Sport Context. Current Opinion in Psychology, 17, 165-169. https://doi.org/10.1016/j.copsyc.2017.05.012

Parent, S., Lavoie, F., Thibodeau, M-E., Hébert, M., Blais, M., \& Team, P. A. J. (2016). Sexual Violence Experienced in the Sport Context by a Representative Sample of Quebec Adolescents. Journal of Interpersonal Violence, 31(16), 2666-2686. https://doi.org/10.1177/0886260515580366

Parkin, W., \& Green, L. (1997). Cultures of abuse within residential child care. Early Child Development and Care, 133(1), 73-86. https://doi.org/10.1080/0300443971330106

Pépin-Gagné, J., \& Parent, S. (2016). Coaching, Touching, and False Allegations of Sexual Abuse in Canada. Journal of Sport and Sport Issues, 40(2), 162-172. https://doi.org/10.1177/0193723515615176 
Pringle, H. (1993). Acting like a man: Seduction and rape in the law. Griffith Law Review, 2(1), 64-74.

Renfree, G., \& Kohe, G. Z. (2019). Running the club for love: challenges for identity, accountability and governance relationships. European Journal for Sport and Society. https://doi.org/10.1080/16138171.2019.1623987

Rintaugu, E. G., Kamau, J., Amusa, L. O., \& Toriola, A. (2014). The forbidden acts: Prevalence of sexual harassment among university female athletes. African Journal for Physical, Health Education, Recreation and Dance, 20(3), 974-990.

Romijn, D., Van Kalmthout, J., Breedveld, K., \& Lucassen, J. (2013). VSK-monitor 2013 Voortgangsrapportage Actieplan "Naar een veiliger sportklimaat". Utrecht, The Netherlands: Mulier Instituut.

Scharpf, F. W. (1994). Games real actors could play: positive and negative coordination in embedded negotiations. Journal of Theoretical Politics, 6(1), 27-53. https://doi.org/10.1177/0951692894006001002

Scott, T. A. (2015). Analysing Policy Networks Using Valued Exponential Random Graph Models: Do Government-Sponsored Collaborative Groups Enhance Organizational Networks?. Policy Studies Journal, 44(2), 215-244. https://doi.org/10.1111/psj.12118

Simon, H. A. (1969). The sciences of the artificial. Cambridge, MA: The MIT Press.

Sørensen, E., \& Torfing, J. (2012). Collaborative Innovation in the Public Sector. The Innovation Journal: The Public Sector Innovation Journal, 17(1), 1-14. https://doi.org/10.1093/oxfordhb/9780199560530.013.0015

Stevens, V. (2018). Individual learning behaviour in collaborative networks. This is a chapter. In Dunlop, C., C. Radaelli, and P. Trein, Learning in Public Policy: Analysis, Modes and Outcomes. Palgrave-MacMillan, Basingstoke, United Kingdom.

Stevens, V. (2019). How can digital tools foster citizen participation and democracy? An examination of a digital democracy process in Amsterdam-West, the Netherlands. Paper presented at the 2019 EGPA conference, Belfast, UK, September 10-14.

Stevens, V. (2019). The new method of Exponential Random Graph Modelling to analyze interactions in participatory processes of place branding. The Marketing Review. (forthcoming).

Stevens, V., \& Verhoest, K. (2016). A next step in collaborative policy innovation research: analysing interactions using Expontential Random Graph Modelling. The Innovation Journal: The Public Sector Innovation Journal, 21(2), 1-20.

Teodoro, M. P., \& An, S. H. (2018). Citizen-Based Brand Equity: A Model and Experimental Evaluation. Journal of Public Administration Research and Theory, 28(3), 321-338. https://doi.org/10.1093/jopart/mux044

Tiessen-Raaphorst, A., Lucassen, J., Van den Dool, R., \& Van Kalmthout, J. (2008). Weinig over de schreef. [Online] Available:

https://www.scp.nl/Publicaties/Alle_publicaties/Publicaties_2008/Weinig_over_de_schreef. Tillyer, M. S., Gialopsos, B. M., \& Wilcox, P. (2016). The Short-Term Repeat Sexual Victimization of Adolescents in School. Crime \& Delinquency, 62(1), 81-106. 
https://doi.org/10.1177/0011128713501026

Toftegaard, N. J. (2004). Idraettens Illusoriske Intimitet. Copenhagen, Denmark: Kobenhavns Universitet press.

Vertommen, T., Kampen, J. K., Schipper-van Veldhoven, N., Uzieblo, K., \& Van Den Eede, F. (2018). Severe interpersonal violence against children in sport: Associated mental health problems and quality of life in adulthood. Child Abuse \& Neglect, 76, 459-468. https://doi.org/10.1016/j.chiabu.2017.12.013

Vertommen, T., Kampen, J. K., Schipper-van Veldhoven, N., Wouters, K., Uzieblo, K., \& Van Den Eede, F. (2017). Profiling perpetrators of interpersonal violence against children in sport based on a victim survey. Child Abuse \& Neglect, 63, 172-182. https://doi.org/10.1016/j.chiabu.2016.11.029

Vertommen, T., Schipper-van Veldhoven, N., Wouters, K., Kampen, J. K., Brackenridge, C. H., Rhind, D. J. A., ... \& Van Den Eede, F. (2016). Interpersonal violence against children in sport in the Netherlands and Belgium. Child Abuse \& Neglect, 52, 223-236. https://doi.org/10.1016/j.chiabu.2015.10.006

Volskrant (2017a). Seksueel Misbruik bij PSV en Vitesse Twee Oud Jeugdspelers treden naar Buiten. [Online] Available:

https://www.volkskrant.nl/nieuws-achtergrond/seksueel-misbruik-bij-psv-en-vitesse-twee-ou d-jeugdspelers-treden-naar-buiten b2ef6057/.

Volskrant (2017b). Hij hield mijn hand vast en bewoog hem heen en weer. [Online] Available: https://www.volkskrant.nl/sport/-hij-hield-mijn-hand-vast-en-bewoog-hem-heen-en-weer- b0 96dca5/.

Waardenburg, M. (2016). Which wider social roles? An analysis of social roles ascribed to voluntary sports clubs. European Journal for Sport and Society, 13(1), 38-54. https://doi.org/10.1080/16138171.2016.1153883

Wagenmans, A., Van Minnen, A., Sleijpen, M., \& De Jongh, A. (2018). The impact of childhood sexual abuse on the outcome of intensive traumafocused treatment for PTSD. European Journal of Psychotraumatology. https://doi.org/10.1080/20008198.2018.1430962

Wäsche, H., Dickson, G., Woll, A., \& Brandes, U. (2017). Social network analysis in sport research: an emerging paradigm. European Journal for Sport and Society, 14(2), 138-165. https://doi.org/10.1080/16138171.2017.1318198

\section{Copyright Disclaimer}

Copyright for this article is retained by the author(s), with first publication rights granted to the journal.

This is an open-access article distributed under the terms and conditions of the Creative Commons Attribution license (http://creativecommons.org/licenses/by/4.0/). 